This is the final peer-reviewed accepted manuscript of:

Munari F., Sobrero M., Toschi L. (2017) Financing Technology Transfer: Assessment of university-oriented proof-of-concept programmes, Technology Analysis and Strategic Management, 29(2): 233-246

The final published version is available online at:

https://doi.org/ 10.1080/09537325.2016.1241874

Rights / License:

The terms and conditions for the reuse of this version of the manuscript are specified in the publishing policy. For all terms of use and more information see the publisher's website. 


\section{Financing Technology Transfer: Assessment of University-Oriented Proof-of-Concept Programs}

This study analyses the characteristics of the proof-of-concept (POC) programs initiated by university and public research organizations in Europe, as a mechanism to address funding gaps and improve the transfer of research-based inventions to markets. We contribute to the literature on investment readiness of new ventures and on financing technology transfer by assessing the structure of such funding instruments and identifying critical success factors for their design and implementation. The analyses rely on 7 in-depth case studies of university-oriented POCs in Europe.

Keywords: proof of concept programs; university; technology transfer; Europe

JEL Classification: G29 L26 M13 O32

\section{Introduction}

Universities play a pivotal role in the society by educating and generating new knowledge. In addition to the two original missions of teaching and research many universities have increasingly taken action to develop a 'third mission', by facilitating knowledge transfer (Etzkowitz et al., 2000). Knowledge transfer is "the commercialization of public research from universities and public research organizations (PROs) so as to generate economic and social value and industry development" (OECD, 2013: 13), through a variety of modes and channels. Amongst such channels, technology transfer (TT) more narrowly refers to licensing of patented or otherwise protected inventions, as well as academic entrepreneurship (Perkmann et al., 2013).

The commercial exploitation of new discoveries is thus a widespread, added component to the activities of modern universities and PROs, as it represents an immediate and measurable market acceptance for outputs of academic research. Previous research, however, shows that the so-called funding gap, which highlights the existence of huge 
demand for finance on one side but a limited supply on the other, limits the transformation of new inventions into successful products or services (Rasmussen, Moen, and Gulbrandsen, 2006; Wright et al., 2006). This gap mostly applies to "embryonic" university-generated inventions, which tend to represent the frontier of scientific advancements, involving high information asymmetries with potential investors (Colyvas et al., 2002; Jensen and Thursby, 2001; Bjørguma and Sørheim, 2014).

Given the importance of TT process and, at the same time, the barriers to its effective realization, several universities and public agencies have implemented initiatives that support TT activities from academia to industry, including university accelerators, incubators, start-up competitions, and university-managed seed funds (Clarysse et al., 2005; Munari and Toschi, 2014; Munari, Pasquini and Toschi, 2014; Munari et al., 2015; Rasmussen and Soreheim, 2012).

In this area, university/PRO-oriented proof-of-concept (POC) programs represent a recent and innovative mechanism, widely embraced by public policies (e.g., U.S. Startup Initiative, EU Horizon 2020 Framework). POCs encompass several funding schemes that combine money, expertise, and training to help new inventions lower their technological uncertainty at an early stage and validate their technical and commercial feasibility. This type of support, thus, applies a demand-side approach at the funding gap in order to decrease the level of risk of research projects and, at the same time, increase the attractiveness to demonstrate their commercial value and investment readiness (Mason and Harrison, 2004) to potential industrial partners and investors.

Research in this emerging area remains limited and mostly based on single case studies or anecdotal evidence (Gulbranson and Audretsch, 2008) or single countries (Bradley et al., 2013; Maia and Claro, 2013; McAdam, McAdam, and Brown, 2009; Rasmussen, 
2008). Multi-country studies are absent, which makes it difficult to understand the characteristics POCs should have to effectively address the "funding gap" issue.

To fill these gaps in the literature, this study seeks a better understanding of a set of POCs initiated by European universities and PROs, in order to investigate the following research question:

What are the main characteristics that POCs should have in order to effectively address the "funding gap" issue and increase the investment readiness of commercialisation projects emerging from universities and PROs?

We provide answers to this question exploiting data gathered through in-depth interviews with 7 TTO managers of 7 European universities/PROs managing internal POCs.

We contribute to the literature on entrepreneurial finance and technology transfer by responding to an open call for investigating new methods and mechanisms for financing scientific and innovation activities (Aghion et al., 2009). By so doing, we contribute to the literature on "funding gap" and investment readiness (Mason and Harrison, 1996), to show how the design of POCs may support the resolution of the demand side of the funding gap issue. To our knowledge, this is the first contribution adopting a cross-national perspective in the analysis of POCs, thus helping to identify specific contextual factors which affect the effectiveness of this type of instruments. Besides that, for the first time we investigate what determines the effectiveness of this type of funding gap instruments, moving beyond simple anecdotal or descriptive approaches.

In the next sections, we present the main literature to which we intend to contribute. We then discuss the rationale for relying on POCs to enhance TT. The sample and methods are presented in Section 3. In Section 4, we discuss our seven cases in depth. We conclude with a discussion of the policy and managerial implications of our findings.

\section{Literature Review}




\section{Origins of the funding gap}

To start and grow an innovative business requires financial capital. Thus, access to finance is a central priority, related to the ability of young and innovative companies to obtain the most appropriate source of finance applicable to their stage of development (Harris, 1995). Young and innovative businesses, by their nature, do not have access to the same resources as more established larger firms, due to evident risks associated with the uncertainty of project outcomes, significant asymmetric information with potential investors and a limited presence of incomes warranted in the short term (Murray, 1998). Venture capitalists (VCs), providing equity finance, are specialized investors prone to invest in risky projects and, thus, have an active role in the funding of high potential, early stage enterprises (Wright et al., 2006).

However, the literature on entrepreneurial finance highlights the existence of a funding gap, with huge demand for finance on one side and a limited supply on the other. Factors from the supply side that lead investors to prefer larger deals in order to finance later-stage companies are the presence of information asymmetries, high transaction costs and ongoing running costs, high risk and lack of exit options. From the demand side, instead, the main factor is related to the lack of 'investment readiness' by new ventures. In the specific case of academic spinoffs (ASOs), the problem of funding gap is particularly relevant due to the "embryonic" nature of university-generated inventions, which tend to represent the frontier of scientific advancements and thus involve considerable resources, risks and time in terms of their subsequent validation. VC firms tend typically to focus on "hot" technologies that can generate short-term exit opportunities, but bypass other projects that may have greater impacts but that require a long-term perspective (Lockett and Wright, 2005). For these reasons, private VC funding may not be readily available to early-stage ASOs.

To sum up, what is agreed in the literature is that demand for entrepreneurial finance is unquestionable, meaning that attention has tended to focus on the supply of finance, mainly on increasing the availability of funding opportunities and investors. However, providing 
more cash alone will not be enough to solve the funding gap. A different stream of the literature has emphasized that many new ventures fail to raise external equity finance because projects are not "ready" to be financed. This is particularly critical in the case of ASOs, as we better explain in the next section.

\section{The investment readiness of new ventures and academic spin-offs}

The term investment readiness was originally coined in a report by Australia's Marsden Jacob Associates and National Investment Council (1995: 1), which defined it as the enterprise's ability "to meet fundamental requirements to be attractive to external investors". Becoming investment ready is a transformational process by which an early stage company acquires "much needed sector specific expertise, sophisticated managerial disciplines or robust commercial acumen". Mason and Harrison (2004), instead, suggest that entrepreneurs are not investment ready when they are "either unwilling, or do not know, how to meet the requirements of investors, or even know what these requirements are.

The "investability" of the project - referring to the extent to which the business meets the requirements of external investors - is thus central (Toschi and Murray, 2009). Several studies examined the reasons why most new ventures that seek external finance do not meet such requirements (Mason and Harrison, 1996; Mason and Rogers, 1997): weaknesses in the entrepreneur/management team; lack of strategic focus; marketing and market-related factors, notably flawed or incomplete marketing strategies; limited growth prospects of the business; flawed financial projections

In the specific case of ASOs, the concept of investment readiness is related to other barriers and inefficiencies that limit the transformation of new, research-based inventions into successful products or services. One of such barriers is the so-called knowledge gap (Rasmussen et al., 2006; Wright et al., 2006). Scientific excellence might not coincide with success in organizing a new venture. When researchers and academics are involved, technical 
skills may be in abundance, but managerial and commercial skills are scarce (Allen, 1977).

Several works thus recommend that ASOs develop stronger relations with industry to access the commercial abilities needed to reach the market with their technologies (Munari and Toschi, 2011; Shane and Stuart, 2002; Wright et al., 2006).

A second important barrier limiting the investment readiness of ASOs is related to the differences in values and language between academics and potential investors (Knockaert et al., 2010), which may create a communication gap, thus limiting the ability of the academic teams to access external funding. Professional financial investors may find it difficult to understand scientific reports and communicate with university researchers, scientists generally lack awareness and understanding of business culture and the requirements of the investment process (Rasmussen and Rice, 2012).

Previous studies thus suggest that the lack of quality in terms of "investability" of new ventures (and ASOs in particular) is a major issue, limiting the possibility of access to external finance. However, less clear is the understanding of which specific solutions may be implemented in order to address these barriers in the specific case of ASOs. How to effectively combine funding and support in order to increase the attractiveness of ASOs toward external investors remains an open question.

\section{Empirical evidence on university-oriented POCs}

The focus of our paper is on a particular type of financial mechanisms, Proof of Concept programs (POCs), developed by universities and PROs to address the demand side of the funding gap and, thus, increase the level of maturation and investment readiness of their commercialisation projects. POCs include funding schemes (e.g., grants, repayment schemes, loans) that combine money, expertise, and training to help university researchers demonstrate the feasibility of their new discoveries, whether technically, in terms of manufacturing, or commercially. The ultimate goal is to bring the technology to a point that it can be licensed to 
external industrial partners or a start-up can be created, which would attract the interest of investors in subsequent development stages (Guldbranson and Audretsch, 2008; Bradley, Hayter, and Link, 2013).

In the first analysis of two pioneering examples of POC (the Deshpande Center at MIT and the von Liebig Center at the University of California), Gulbranson and Audretsch (2008) offer in-depth case studies, describing the conditions that determined their initiation. The differences emerging between the two programs clearly indicate the need to focus on implementation choices, to ensure that POCs fit the environment in which they get applied.

Rasmussen and colleagues (2012) consider government policies in Canada, Finland, Ireland, Norway, Scotland, and Sweden and distinguish among proof-of-concept funding, preseed funding, seed funding, according to the goals sought. Although the work highlights widespread attention to common problems and a general convergence toward well-identified policy models, it cannot offer any meaningful evaluation of single policies, either directly or comparatively. Similar limits mark other studies of POCs, such as the works by Maia and Claro (2013) for the Portugal Innovation Ecosystem , or by Bradley et al. (2013) for the U.S. context.

McAdam (2009) and Rasmussen et al. (2012) instead focus on the researchers who benefit from such programs. The former study applies an absorptive capacity framework to six successful POC projects run within a university in Northern Ireland and demonstrates the key role and influence of the principal investigator, as well as the importance of operational procedures and competencies held by the people running the programs. Rasmussen, Mosey, and Wright (2011) instead selected two case studies in U.K. and two in Norway, to document that the presence of specific support programs was instrumental in facilitating the development of venture creation competencies. 
Although interest in POCs is strong, extant literature still has not yet addressed several pertinent issues. From a theoretical point of view, although it is widely accepted that POCs are mechanisms set up with the aim to reduce the technological uncertainty of research projects and thus, support and facilitate the commercialization of research, it has not been conducted any investigation to precisely understand under which specific characteristics POCs can effectively address the demand side of the funding gap. In particular, we will show how to design these programs to address the roots of the funding gap and what type of external conditions matter. We refer to the funding gap theoretical framework and adopt a multi-country approach to investigate the main issues related to POCs structure and design and the characteristic of the institutional environment in which they are called to operate.

\section{Methods}

In order to identify university oriented POC progams in Europe, we initially completed a survey to university TTO managers. The survey was conducted in 2013 with 657 professionals from 559 university TTOs across 32 European countries ${ }^{1}$. We were able to obtain 135 responses from universities in 28 European countries. In the survey, 49 universitymanaged POC programs were mentioned. From that list, we selected seven illustrative cases, described in Table 1, which are particularly interesting for the objectives of our study. Although they all represent significant experiences with internally managed POCs, the cases show heterogeneous characteristics and various institutional contexts, to help identify factors that might affect program success in addressing the funding gap. Thus, the cases differ in their timing, the extent of activation, scope, the degree of specialization of their promoting universities and the stage of development in the local ecosystem. For each case, we conducted direct interviews of two hours with the TTO professionals in charge of the programs, guided

\footnotetext{
${ }^{1}$ A detailed description of the survey is provided in the paper by Munari et al. (2015).
} 
by an ad-hoc questionnaire. We collected further information about the POCs through detailed analyses of secondary data sources (TTO annual reports, program websites and accompanying documents).

--- Include Table 1 around here ---

\section{Analyses and Main Findings}

\section{Analytical framework}

The set of interviews we performed clearly indicate that, in order to enhance the investability of commercialisation projects emerging from universities and PROs, it is critical that two conditions are satisfied by POC programs: (i) the structure of POC should be designed in order to effectively address the main constraints at the basis of the funding gap; (ii) adequate external conditions, in terms of organizational and institutional environment, should be in place in order to provide an effective support. Figure 1 presents our conceptual framework, derived from the analysis of the interviews, linking the design and structure of the POC programs and the supportive environmental conditions to the enhanced investment readiness levels of university technologies and spin-off projects. In our framework, 4 influential factors concern the design of POCs (size of funding, selection criteria, tight control and milestonebased structure, additional support) and 3 influential factors are related to external conditions (university research quality, TTO expertise and public support). They are discussed in more length in the following sections.

--- Include Figure 1 around here ---

\section{The design and structure of POC programs}




\section{Size of funding}

According to our interviews, to effectively address the funding gap, POCs should be adequately funded to support the projected lifetime, the expectations of the stakeholders involved, and future potential sustainability. Insufficiently endowed programs spread their resources too thinly across projects and thus cannot provide sufficient support to confirm the industrial feasibility of each new technology or guarantee a long enough time horizon to fine tune and learn from inevitable mistakes. In the cases analysed, the maximum amount of funding provided per project ranges from $23,000 €$ to $60,000 €$ for early-stage and smaller POCs and from $93,000 €$ to $300,000 €$ for second-stage and larger programs. The smallest, most recently established POC programs funds an average of 3 projects per year, whereas the largest fund around 20. This difference depends on both differences in the level of experience and funds managed, as well as on the need to create a proper deal flow to select the projects. The majority of the programs analyzed are based on grants

\section{Staged capital infusion}

As a corollary to the previous point, there is the necessity for program managers to have a plan and contacts for securing follow-on funds, so to effectively promote the progression of technologies to license-ready status or the formation of spin-offs companies which satisfy the investability requirements by business angels and VCs. This aspect is particularly important to address the knowledge gap, as only valuable projects with an appropriate level of maturation and a lower level of information asymmetries, may proceed in the investment process. A way to deal with this issue is to manage multiple POCs with a structured approach, where financing proceeds in stages, so to manage the different uncertainties, typical of the projects funded and help investee teams to use the money at the correct timing, for specific purposes and in the best way. This type of approach derives from the venture capital market, in which investments proceed with 
steps (Gompers and Lerner, 2001). In the cases reported in Table 1, we can identify four first-stage POCs offering smaller monetary amounts $(25,000 €-50,000 €)$. In such cases, the second stage of funding provides more money $(80,000 €-250,000 €)$ for projects that successfully completed the previous stage and needed further development. The experience of UCL Business illustrates well this approach. Early-stage projects initially receive funding from different POCs managed by the TTO, with a limited amount of money (up to 25,000 GBP per project). Then a subsequent round of pre-seed financing (up to 100,000 GBP) is available from a fund managed at the university level by a dedicated steering group. After that point, funded technologies should be able to access external development funding from public or private agencies, business angels and seed capital funds.

\section{Tight selection process}

The methods used to screen and select applications are extremely relevant in order to direct the money to the most promising projects and in the quickest way. It is important that the investment criteria are clearly stated and communicated to the researchers and partners involved, as transparency and rule clarity contribute to the establishment of a climate of trust between the researchers, the TTO staff and the parties involved during the development of the technologies. This aspect simultaneously addresses the knowledge and communication gaps characterizing investments in ASOs, accordingly with the general practice followed by VC investors (Baum and Silverman, 2004; Munari, Odasso and Toschi, 2011; Munari and Toschi, 2014).

Among our case studies, the selection criteria are relatively homogenous, with a focus on the assessment of the technological potential, the market potential and commercialization opportunities, and the quality of the valorization plan. With regards to the selection process, some TTOs launch calls for applications, followed by a selection 
process among submitted projects (KTH, University of Ulster, VU Amsterdam, Skoltech). Other TTOs prefer to select projects for POC funding on a rolling basis, from a pool of projects that are being developed with the support of the TTO (UCL, EPFL). The cases also show that the selection of POC projects can be undertaken directly by the TTO or involve a broader committee composed also by scientists and external TT experts (TT consultants, industry representatives, business angels or venture capitalists). The former solution helps avoid long, bureaucratic procedures that could burden the process. From its start, UCL Business adopted this approach for its internally managed POCs. Within such programs, single business managers responsible for different technological fields have the autonomy to decide which projects receive the available funding $(25,000$ GBP per project), after a rapid due diligence process that typically involves other colleagues of UCL Business. Another TTO Director described a similar process:

\footnotetext{
"From inception, our vision was that the decision process should be fast and simple. Any researcher or student with an innovation project is invited to submit his or her idea in a very informal manner to the program manager. A critical step is a meeting where the idea is discussed, its potential assessed, and, more importantly, the motivation of the project owner evaluated. A simple due diligence is then added, involving contacts from the university and the local innovation ecosystem. If the analysis is positive, the candidate is asked to send a two-page proposal that describes the project more formally. The final selection of the awardees is then completed by the internal committee of the TTO”.
}

The latter solution is particularly suited for POC rounds awarding larger funding blocks, as in the case of later-stage, larger POCs. In such cases, an investment committee typically is created, responsible for the ultimate selection of projects to fund. The interviewees noted the importance of involving external industry partners or private VC firms, in addition to representatives from the TTO and the university, to enhance the committees' ability to select projects with greater commercialization potential. This 
solution presents specific advantages, such as the possibility to rely on the market and industrial expertise of external partners to better assess the innovation potential of technologies, or the possibility to reduce conflicts with researchers about projects not accepted for POC funding.

\section{Support for competence-building and networking}

All the programs rely on an underlying, fundamental assumption that transforming a research result or idea into a commercial product or service requires competences and skills that generally are not possessed by the researchers. Therefore, they recognize that they also must address knowledge gaps related to various topics, such as IPR and regulations, market assessments, business development, financing, business case presentations, and project management. In our focal case studies, support for awardees came in different forms, including (a) a dedicated program manager who helped the research team prepare the submission and then follow up; (b) a team of experts from the TTO, usually led by a business manager; or (c) the TTO staff in collaboration with external actors, such as business incubators or university training programs. Consider the following examples offered by the interviewed TTO managers:

"Every project backed by the program is followed by a business development coach that follows the project and gives the support needed to move forward. Our vision is to be the most marketoriented innovation support organization in our country. This means that we want all our ideas to meet the market, by getting a market feedback from a very early stage, and finally making a deal with a paying customer".

"In the post-investment phase, a team is formed in which the business manager is assisted by a project manager, and experts from the IP and regulatory groups". 
Providing dedicated support for different managerial and legal aspects, as well as specific networking opportunities, is both an asset for the funded principal investigators to become more investment ready and a way for the funders to monitor the project, control deadlines, and decrease the level of information asymmetry about the progress achieved.

\section{The supportive institutional environment}

\section{Characteristics of the university research base}

Universities represented in our case-studies vary from large, highly prominent cases such as UCL or EPFL to the more local University of Ulster or the recently established Skolkovo Institute of Science and Technology. The quality of the research conducted and the scope of disciplines covered emerge from the interviews as key factors that both ensure a wider applicant pool and strengthen the selection process. Regional solutions emerge mainly when single institutions are less prominent in their size or quality, with the goal to increase the pool eligible for the program and thus enhance the likelihood of finding high quality projects. For example, at Skolkovo, the first POC was modeled explicitly on the experience of the MIT Desphande Center, though adapted to the Russian context and including other institutions as the hiring of faculty progressed.

\section{Size and expertise of the TTO}

According to the interviews, minimum levels of TTO staffers and resources are required to manage internal POCs effectively. As two TTO managers explained:

\footnotetext{
"You need to have an IP budget, professionalized business managers, and a POC if you want to undertake TT activities from universities and public research successfully. Critical mass is also important. Small universities should team up among themselves or with more experienced partners if they want to establish similar initiatives".
} 
"You need very special types of people to do this job, having one leg in academia and one leg in business."

The importance of building TTOs that combine expertise for evaluating research projects from an industrial perspective, together with an ability to communicate across groups separated by their jargon, priorities, and expectations, is clear. POCs also require to play a more proactive role, since the effective functioning of a POC program, according to almost all respondents, is very much about people interactions and relationships. For TTO officials and program managers, therefore, it's very important to build connections and engage researchers, from the one hand, and with different actors of the local ecosystems, such as companies, investors, public authorities, other supporting institutions.

The solicitation of external experts and mentors offers a good alternative to finding permanent TTO staff, especially when the long-term sustainability of the program is not certain. This method enables a better selection of specific competence profiles, but it also might conflict with the need for more direct management of the program by the TTOs or require a clearer establishment of conflict-of-interest policies.

\section{Public support}

Our interviews suggest that POCs arose in institutional contexts that were highly supportive toward innovation and technology transfer, coherently with the results of previous literature (Guldbranson and Audretsch, 2008). Almost all POCs we analysed benefited from specific, public support provided by national or regional innovation agencies (Flemish Innovation Agency for KU Leuven; Swedish Innovation Agency Vinnova for KTH Innovation; London Development Agency and HEIF/IPSRC for UCL; Invest Northern Ireland for University of Ulster; Swiss Innovation Agency CTI for EPFL; Dutch national government for VU 
Amsterdam). In two cases, POCs relied also on private funds (the company Johnson \& Johnson supporting a POC at UCL, and INEOS, Helbling, and Lombard Odier supporting the EPFL Innogrants). The collaboration among university managers, TTO managers, and external stakeholders from national and regional public institutions should therefore be a critical area of attention for implementing these types of programs.

Also, building an effective POC cannot be accomplished in just a few years. The returns likely take years to manifest, at least in financial terms, as noted by the director of one of the most successful and renowned TTOs:

"The TTO in our university was established a few decades ago. However, it took almost 15 years to really have an impact...."

Another director of a different TTO offered a similar assessment:

"It has been a beneficial exercise, it has provided economic value for money, but it has taken a very long time. So, you need a lot of projects and you need to be patient."

The decision makers (both at the university-level and at the government level) must remain committed and undaunted by potential early failures (e.g., low rate of returns), such that they enhance their support following early problems. This commitment also requires a willingness to experiment, evaluate, and fine-tune the support provided, in line with early feedback received.

\section{Conclusions}

Our study represents an initial attempt to analyse university-oriented POCs in Europe and contribute to the increasing literature on investment readiness of new ventures and finance for technology transfer (Mason and Harrison, 2004; McAdam and Marlow, 2011; Rasmussen, 2008; McAdam, McAdam, and Brown, 2009; Croce, Grilli and Martinu, 2013), by shedding light on the effective design of such innovative financial instruments. The evidence from 
seven case studies suggests several elements that can guide the development of dedicated POC initiatives at the university level and offer a clearer sense of the conditions required for their implementation.

\section{Contributions to prior literature}

This article adds to the debate in the funding gap and investment readiness literature (Mason and Harrison, 1996; Salmenkaita and Salo, 2002) by confirming that, in the specific case of university technologies and spin-offs, the gap is not only about the lack of capital, but also of competencies and communication skills (Knockaert, Spithoven, and Clarysse, 2010; Rasmussen, Mosey, and Wright, 2011). Thus, introducing demand-side initiatives that encompass a wider set of support activities (mentoring, training, networking) is critical. Also, we contribute to the emerging literature on financing technology transfer (Croce, Grilli and Martinu, 2014; Rasmussen and Sorheim, 2012; Munari et al., 2015; Wright et al., 2006) by illustrating how to effectively design POCs as innovative forms of demand-side instrument to enhance the commercialization of university technologies. Whereas previous studies have focused on initiatives by single universities (Gulbranson and Audretsch, 2008; Maia and Claro, 2013), our comparative analysis has revealed a set of specific design characteristics of such programs that directly address the deficiencies in the investability of ASOs. Finally, our investigation of a diversified set of institutions and countries helps to shed light on the role of external conditions at the university-, TTO- and environment-level, required for the successful implementation of POCs. In particular, previous research has shown that the number of people engaged at the TTO and their experience are important determinants of a successful transfer, because it requires time, skills and effort to break through existing cultural barriers that separate the TTO, university scientists and industry, and encourage a more favorable climate for commercialization (O'Shea et al., 2005; Schoen et al., 2014). 
Our findings confirm and extend such results in the specific context of POC programs, showing the role of dedicated human capital as a key success element.

Our study has clear limitations, in part related to the attempt to explore a relatively recent phenomenon for European universities, which point out promising avenues for future research. First, a consensus about how to measure the success or failure of these initiatives is lacking. Although some measures (number of licensing agreements generated, number of ASOs generated, ability to attract follow-on funding by external investors or ability to generate revenues) were commonly used in our cases, there was a common perceived need to find a more comprehensive set of metrics. We thus need new ideas on how to assess and compare the different experiences in this area. We also call for further research that analyses whether academic technologies supported by POCs have a greater likelihood of being commercially exploited and generating revenues than a sample of not supported technologies.

Additional investigations should quantitatively assess the ultimate economic and social impacts of POCs. Moreover, given the importance of policy intervention as fundamental lever for the activation of such instruments, future research should analyse the most suitable policy approaches in order to enhance the impact of POCs. Finally, the entire funding process for these instruments needs investigation, taking into consideration the mechanisms by which TTOs add value to projects, the micro-dynamics among the actors involved, and the forms of interaction that emerge to maximize the effectiveness of communication across different levels.

\section{Implications for university and government decision-makers}

In terms of managerial and policy implications, a first clear message that emerges from our case-studies refers to the importance of POCs as instruments to improve the investment readiness of projects generated from university research. The availability of well-designed and well-functioning POCs emerges as a critical component in a technology transfer ecosystem. 
Second, considering the importance of guaranteeing the availability of these instruments, our findings also highlight that they should not necessarily be activated and managed by a single university/PRO. With regard to university-level factors, two characteristics emerge as particularly critical preconditions for understanding when universities should adopt internal gap funding instruments for technology transfer: (1) the size and excellence of university scientific production; and (2) the size and expertise of the TTO. Collaborative or regional/national solutions should emerge mainly when single institutions are less prominent in their size or quality.

Third, qualified human capital is essential, especially with regard to the specific advice required, the typical characteristics of principal investigators and TTO officers, and the blurred boundaries between this activity and services offered by professional consultants or codevelopers. Besides these general external conditions, our analyses reveal a series of critical success factors for the design of POC programs: the adequate funding size of the program, the staged infusion of capital and tight management of the process, the amount of funding provided to the projects. All such conditions are required in order to take a proactive approach to support the creation of ASOs able to become interesting investment cases.

\section{Acknowledgments}

Financial support from the EIBURS Programme of the European Investment Bank for the "Financing Knowledge Transfer in Europe" (FinKT) Research Project and from MIUR for the PRIN Project "Market and Non-Market Mechanisms for the Exchange and Diffusion of Innovation" is gratefully acknowledged. 


\section{References}

Aghion, P., David, P. A., \& Foray, D. 2009. Science, technology and innovation for economic growth: linking policy research and practice in 'STIG Systems'. Research Policy, 38, 681693.

Allen, T. 1977. Managing the flow of technology. MIT Press, Cambridge, MA.

Baum, J.A.C., and B.S. Silverman. 2004. Picking winners or building them? Alliance, intellectual, and human capital as selection criteria in venture financing and performance of biotechnology startups, Journal of Business Venturing, 19: 411-436.

Bjørguma, O., and R. Sørheim, 2014. The funding of new technology firms in a pre-commercial industry - the role of smart capital. Technology Analysis \& Strategic Management, 27, no. 3: 249-266.

Bradley, S.R., C.S., Hayter, and A.N. Link. 2013. Proof of concept centers in the United States: An exploratory look. Journal of Technology Transfer. 38, no. 4: 349-381.

Clarysse, B., M., Wright, A., Lockett, E., Van de Velde, and A. Vohora. 2005. Spinning out new ventures: a typology of incubation strategies from European research institutions. Journal of Business Venturing. 20: 183-216.

Colyvas, J., M., Crow, A., Gelijns, R., Mazzoleni, R.R., Nelson, N., Rosenberg, and B.N. Sampat. 2002. How do university inventions get into practice? Management Science, 48, no. 1: 61-72.

Croce, A., L., Grilli, and S. Martinu. 2013. Venture capital enters academia: A Look at University- Managed Funds. Journal of Technology Transfer, DOI 10.1007/s10961-0139317-8.

Etzkowitz, H., A., Webster, C., Gebhardt, and B.R.C., Terra, 2000. The future of the university and the university of the future: evolution of ivory tower to entrepreneurial paradigm. Research Policy 29: 313-330.

Guldbranson, C.A., and D.B., Audretsch. 2008. Proof of concept centers: Accelerating the commercialization of university innovation. Journal of Technology Transfer, 33, no. 2: 249258.

Harris, S. 1995. Managing organizations to address the finance gap: a study of organizations that are doing so, International Journal of Entrepreneurial Behaviour \& Research, 1, no. 3: $63-82$.

Jensen, R., and M. Thursby. 2001. Proofs and prototypes for sale: The licensing of university inventions. American Economic Review, 91, no. 1: 240-259. 
Knockaert, M., A. Spithoven, and B., Clarysse. 2010. The knowledge paradox explained. What is impeding the creation of ICT spin-offs? Technology Analysis and Strategic Change, 224: 479-493.

Lockett, A., and M. Wright. 2005. Resources, capabilities, risk capital and the creation of university spin-out companies. Research Policy, 34: 1043-1057.

Maia, C., and J., Claro. 2013. The role of a proof of concept center in a university ecosystem: an exploratory study. Journal of Technology Transfer, 38, no. 5: 641-650.

Mason, C. M., and R.T., Harrison. 1996. Why Business Angels Say No: A Case Study

of Opportunities Rejected by an Informal Investor Syndicate. International Small Business Journal,14, no. 2: 35-51.

Mason C., and R.T., Harrison. 2004. Improving Access to Early Stage Venture Capital in Regional Economies: A New Approach to Investment Readiness. Local Economy, 19, no. 2: $159-173$.

McAdam, M., and S., Marlow. 2011. Sense and sensibility: The role of business incubator client advisors in assisting high-technology entrepreneurs to make sense of investment readiness status. Entrepreneurship \& Regional Development: An International Journal, 23, no. 7-8: 449-468.

McAdam, R., M., McAdam, and V., Brown. 2009. Proof of concept processes in UK university technology transfer: An absorptive capacity perspective. R\&D Management. 39, no. 2: 192210.

Munari, F., M.C. Odasso and L. Toschi. 2011. Patent-backed finance. In Munari, F., Oriani, R. (eds.), The economic valuation of patents. Methods and applications, Edward Elgar Publishing, Cheltenham, UK.

Munari, F., M. Pasquini, M., and L. Toschi. 2014. From the lab to the stock market? The characteristics and impact of university-oriented seed funds in Europe. Journal of Technology Transfer, 40, no. 6: 948-975

Munari, F., E., Rasmussen, E., L., Toschi, and E., Villani. 2015. Determinants of the university technology transfer policy-mix: a cross-national analysis of gap-funding instruments. The Journal of Technology Transfer, Special issue, DOI: 10.1007/s10961-015-9448-1.

Munari, F., and L. Toschi. 2014. Do patents affect VC financing? Empirical evidence from the nanotechnology sector. International Entrepreneurship and Management Journal, 1 no. 3: 623-644. 
Munari, F., and L. Toschi. 2011. Do venture capitalists have a bias against investment in academic spin-offs? Evidence from the micro- and nanotechnology sector in the UK. Industrial and Corporate Change, 20, no. 2: 397-432.

Munari F., and L. Toschi. 2014. Assessing the impact of public venture capital programmes in the United Kingdom: Do regional characteristics matter? Journal of Business Venturing, 30: 205-226.

OECD. 2013. Commercialising public research. New trends and strategies. Organization for Economic Cooperation and Development, Paris.

Perkman, M. et al. 2013. Academic engagement and commercialisation: A review of the literature on university-industry relations. Research Policy, 42: 423-442.

Rasmussen, E. 2008. Government instruments to support the commercialization of university research: Lessons from Canada. Technovation, 28: 506-517.

Rasmussen, E., O., Bulanova, A., Jensen, and T., Clausen. 2012. The impact of science-based entrepreneurial firms: a literature review and policy synthesis. NF-rapport nr. 3/2012.

Rasmussen, E., Ø., Moen, and M., Gulbrandsen. 2006. Initiatives to promote commercialization of university knowledge. Technovation, 26: 518- 521.

Rasmussen, E., S., Mosey, and M., Wright. 2011. The evolution of entrepreneurial competencies: A longitudinal study of university spin-off venture emergence. Journal of Management Studies, 48, no. 6: 1314- 1345.

Rasmussen E., and R., Soreheim. 2012. How governments seek to bridge the financing gap for university spin-offs: proof-of-concept, pre-seed, and seed funding. Technology Analysis \& Strategic Management, 24, no. 7, 663-678.

Salmenkaita, J.P., and A., Salo, 2002. Rationales for government intervention in the commercialization of new technologies. Technology Analysis \& Strategic Management, 14, no. 2: 183-200.

Shane, S. and T., Stuart. 2002. Organisational endowments and the performance of university start-ups, Management Science, 48, no. 1: 154-170.

Toschi, L., and G., Murray. 2009. A cross-country review on investment readiness programmes: how can small and medium size enterprises increase their attractiveness to equity investors? Working Paper, University of Bologna and Exeter University Business School.

Wright, M., A., Lockett, B., Clarysse, and M., Binks. 2006. University spin-out companies and venture capital. Research Policy, 35, no. 4: 481-501. 
Table 1. Characteristics of the 7 case-studies of POCs.

\begin{tabular}{|c|c|c|c|c|c|c|c|}
\hline $\begin{array}{c}\text { Name of } \\
\text { university }\end{array}$ & UCL & KU Leuven & KTH & University of Ulster & VU Amsterdam & EPFL & Skoltech \\
\hline Name of TTO & UCL Business & LRD & KTH Innovation & Office of Innovation & VU \& VUMC TTO & EPFL TTO & $\begin{array}{l}\text { Center for } \\
\text { Entrepreneurship } \\
\text { and Innovation }\end{array}$ \\
\hline Country & UK & Belgium & Sweden & UK & Netherlands & Switzerland & Russia \\
\hline Name of POCs & $\begin{array}{l}\text { UCL I (technologies } \\
\text { for children); UCL } \\
\text { (tech for eyes); LDA } \\
\text { (spin-off); J\&J } \\
\text { program. } \\
\text { POC managed by } \\
\text { UCL University }\end{array}$ & $\begin{array}{l}\text { Leverage project } \\
\text { grant (IOF - HB); }\end{array}$ & $\begin{array}{l}\text { VfT (Verifiering for } \\
\text { Tillvvaxt) }\end{array}$ & $\begin{array}{l}\text { Proof of Principle } \\
\text { Program; Proof of } \\
\text { Concept Program }\end{array}$ & $\begin{array}{l}\text { Proof of concept } \\
\text { Program }\end{array}$ & $\begin{array}{l}\text { Innogrant; } \\
\text { Enable Proof of } \\
\text { Concept Funding }\end{array}$ & $\begin{array}{l}\text { Skoltech Innovation } \\
\text { Program }\end{array}$ \\
\hline $\begin{array}{l}\text { Date of creation } \\
\text { of first POC }\end{array}$ & 2000 & & 2008 & 2004 & 2012 & 2005 & 2012 \\
\hline $\begin{array}{l}\text { Investors in the } \\
\text { POC program }\end{array}$ & $\begin{array}{l}\text { Internal resources of } \\
\text { UCL Business and } \\
\text { financial support } \\
\text { from external private } \\
\text { and public actors }\end{array}$ & $\begin{array}{l}\text { KU Leuven and } \\
\text { Flemish Innovation } \\
\text { Agency }\end{array}$ & $\begin{array}{l}\text { VINNOVA (Swedish } \\
\text { Innovation Agency) } \\
\text { and KTH Holding }\end{array}$ & $\begin{array}{l}\text { Invest Northern } \\
\text { Ireland; University of } \\
\text { Ulster; European } \\
\text { Regional } \\
\text { Development Funds }\end{array}$ & $\begin{array}{l}\text { National Government } \\
\text { through Valorization } \\
\text { Program }\end{array}$ & $\begin{array}{l}\text { Lombard Odier } \\
\text { Darier Hentsch; CIE } \\
\text { (Swiss Innovation } \\
\text { Agency) }\end{array}$ & Own capital \\
\hline $\begin{array}{l}\text { Average/maxim } \\
\text { um amount of } \\
\text { funding } \\
\text { provided per } \\
\text { project }\end{array}$ & $\begin{array}{l}25,000 £, \text { up to } \\
50,000 £ \text { for POC } \\
\text { managed at the TTO } \\
\text { level; up to } 100000 \\
\text { for POC managed at } \\
\text { the university level }\end{array}$ & $\begin{array}{l}\text { Funding up to } € \\
100,000 \text {. For standard } \\
\text { Leverage Projects, } \\
\text { minimum funding is } \\
€ 50,000 \text {. }\end{array}$ & $\begin{array}{l}\text { Funding is paid in } \\
\text { installments. In the } \\
\text { first step: up to } \\
35,000 \text { euro. In the } \\
\text { second step up to } \\
250,000 \text { euro }\end{array}$ & $\begin{array}{l}\text { Two different } \\
\text { supports: } 1 \text { ) up to } \\
80,000 £ \text { for the } \\
\text { further development } \\
\text { of the technology or } \\
\text { 2) up to } 20,000 £ \text { for } \\
\text { efforts towards } \\
\text { commercialising the } \\
\text { technology }\end{array}$ & $\begin{array}{l}\text { Up to } 100,000 \text { Euro } \\
\text { per project for the } \\
\text { pre-seed loan }\end{array}$ & $\begin{array}{l}\text { Approximately } \\
90,000 \mathrm{CHF}\end{array}$ & $\begin{array}{l}77,000 \text { Euro }(100,000 \\
\text { USD) }\end{array}$ \\
\hline
\end{tabular}




\begin{tabular}{|c|c|c|c|c|c|c|c|}
\hline $\begin{array}{l}\text { Party in charge } \\
\text { of the selection } \\
\text { process }\end{array}$ & $\begin{array}{l}\text { For internal POCs, } \\
\text { the TTO business } \\
\text { managers. For the } \\
\text { POC managed at the } \\
\text { university level, there } \\
\text { is an investment } \\
\text { committee with } \\
\text { professors, external } \\
\text { business and } \\
\text { financial partners, }\end{array}$ & $\begin{array}{l}\text { Internal board } \\
\text { composed of } \\
\text { academic researchers, } \\
\text { LRD staff and } \\
\text { industry experts }\end{array}$ & $\begin{array}{l}\text { KTH Innovation in } \\
\text { collaboration with } \\
\text { KTH Holding AB }\end{array}$ & $\begin{array}{l}\text { Pre-selection by the } \\
\text { University TTO, then } \\
\text { Invest Northern } \\
\text { Ireland completes the } \\
\text { selection process }\end{array}$ & $\begin{array}{l}\text { TTO selects the } \\
\text { applications to be } \\
\text { then submitted to an } \\
\text { Expert Panel } \\
\text { (academic and } \\
\text { industry experts, with } \\
\text { a Chairman appointed } \\
\text { by the TTO). The } \\
\text { TTO makes a final } \\
\text { decision. }\end{array}$ & EPFL TTO & $\begin{array}{l}\text { Expert team } \\
\text { including } \\
\text { representative from } \\
\text { Skoltech Center for } \\
\text { Entrepreneurship and } \\
\text { Innovation (CEI), } \\
\text { partner universities } \\
\text { and industry experts }\end{array}$ \\
\hline $\begin{array}{l}\text { Type of financial } \\
\text { support } \\
\text { provided }\end{array}$ & $\begin{array}{l}\text { Investment with a } \\
\text { repayment in case of } \\
\text { commercialization }\end{array}$ & Grants & Grant in two steps & $\begin{array}{l}\text { Money is given as } \\
\text { investment. }\end{array}$ & $\begin{array}{l}\text { The Proof of concept } \\
\text { program is based on a } \\
\text { grant. The Pre-seed } \\
\text { program is based on a } \\
\text { loan (interest-free). }\end{array}$ & Grant & Grant \\
\hline $\begin{array}{l}\text { Other support } \\
\text { provided }\end{array}$ & $\begin{array}{l}\text { Legal, commercial, } \\
\text { technical, financial } \\
\text { support by the } \\
\text { Business Managers in } \\
\text { charge and the staff } \\
\text { of UCL Business. }\end{array}$ & $\begin{array}{l}\text { LRD staff supports in } \\
\text { the validation of the } \\
\text { project, preparation } \\
\text { of the patent } \\
\text { application, } \\
\text { development study }\end{array}$ & $\begin{array}{l}\text { A business } \\
\text { development coach } \\
\text { helps in preparing } \\
\text { project plans and } \\
\text { market analyses, } \\
\text { presentations, } \\
\text { building contacts } \\
\text { with public and } \\
\text { private financiers, } \\
\text { enhancing business } \\
\text { development. }\end{array}$ & $\begin{array}{l}\text { There is a team } \\
\text { within the TTO } \\
\text { which form the } \\
\text { technology review } \\
\text { group. It reviews the } \\
\text { progress of each } \\
\text { project and conducts } \\
\text { market validation for } \\
\text { each project as it } \\
\text { progresses and goes } \\
\text { to completion. }\end{array}$ & & $\begin{array}{l}\text { Support of the EPFL } \\
\text { TTO, of the nearby } \\
\text { Science Park (PSE) } \\
\text { and its professional } \\
\text { coaches, as well as of } \\
\text { the services of the } \\
\text { Swiss Innovation } \\
\text { Promotion Agency } \\
\text { (CTI) }\end{array}$ & $\begin{array}{l}\text { Mentoring, business } \\
\text { training, advice on } \\
\text { legal and } \\
\text { commercialization } \\
\text { issues, assistance in } \\
\text { negotiations with } \\
\text { potential clients }\end{array}$ \\
\hline
\end{tabular}

Source: Interviews with TTO managers (completed in 2013 and 2014) and TTO websites 
Figure 1. Analytical framework.

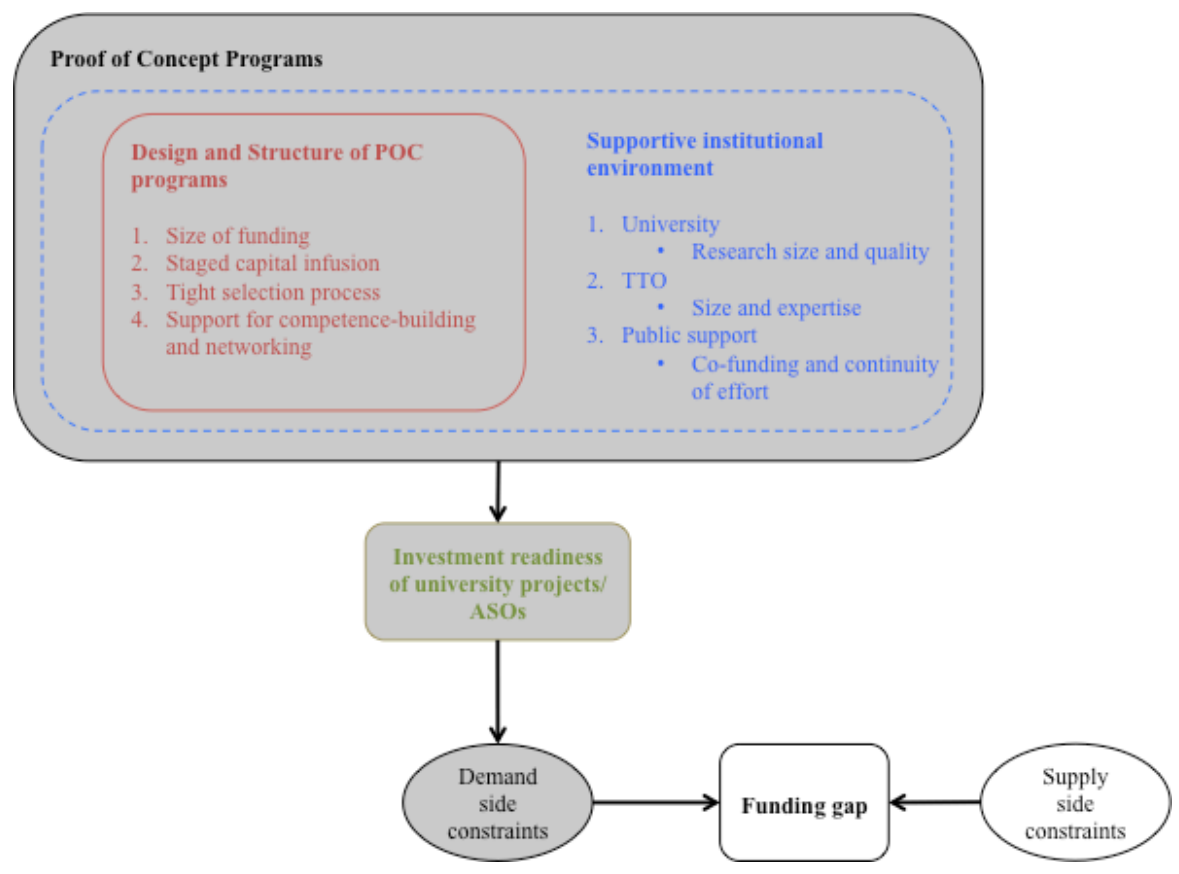

